\title{
Double Left Renal Veins and Multiple Right Renal Veins Found in Japanese Adults
}

\author{
By \\ Junko YAHIRO and Sakuichiro MIYOSHI \\ Department of Oral Anatomy, Fukuoka Dental College, 15-1 Tamura 2, Sawara-ku, Fukuoka, 814-01 Japan \\ - Received for Publication, November 28, $1993-$
}

\begin{abstract}
Key Words: Circumaortic renal venous collar; Multiple right renal veins; Multiple renal arteries; Azygos system veins
Summary: A case of circumaortic renal venous collar, the first such collar to be observed in a Japanese female cadaver, is presented, and its anatomical organization is compared with that in another case in which four right renal veins accompanied four right and three left renal arteries in a Japanese male cadaver. Dobule left renal veins are formed by persistence of a more central retroaortic venous anastomosis, in contrast to multiple right renal veins, which are formed by persistence of some embryonic renal veins arranged in ladder-like patterns. In our case, the dorsal limb of the renal collar communicated with the azygos system veins and lumbar veins. The azygos system veins were considered to have atrophied as a result of some persisting retroaortic venous anastomoses located in the thorax. Therefore, we believe that the renal collar was related to the atrophy of the azygos system veins. To determine whether there are racial differences in incidence of renal collar, further studies in Asians are required.
\end{abstract}

Double left renal veins, which constitute a ring surrounding the abdominal aorta, are referred to as a circumaortic renal venous collar, or renal collar. This has been observed in the West in both whites and blacks (Kramer and Grine, 1980; Seib, 1934) but not in Asians. This is the first report of renal collar in a Japanese adult cadaver. With advances in urological surgery such as renal transplantation and renovascular surgery, this anomaly has more recently been identified by urograph (Goswami, 1976), and computerized tomography (Bartle et al., 1987; Cranston and Halsell, 1991). In contrast to multiple right renal veins, in the persistent renal collar retroaortic venous anastomosis provides communication for collateral circulation of the retroperitoneum. It presents a concomitant risk of hemorrhage (Anson and Dasler, 1961; Babaian and Johnson, 1979; Baldridge and Canos, 1987). Therefore, an anatomical and embryological understanding of venous anomalies is essential. The developmental derivation of a renal collar has been discussed and compared with that in reported cases of multiple right renal veins accompanied by multiple renal arteries (Ohmori et al., 1983). Although multiple renal veins and arteries are often reported separately, there are a few reports describing combined multiple renal veins and arteries (Anson and Dasler, 1961; Pick and Anson, 1940; Rupert, 1915). Finally, the azygos venous systems communicating with the renal collar in the present case are considered.

\section{Materials and Methods}

Specimen I was obtained from a 90 -year-old Japanese female cadaver, and specimen II from a 67-year-old Japanese male cadaver. For the observation of the parietal organs, the viscera of the cavum were carefully removed and the renal vasculature was dissected, along with its tributaries and the lumbar and azygos venous systems. After observation and photography in situ, the renal vasculature and kidneys were carefully removed and rephotographed. The latter set of photographs was used to draw the diagrams in this article.

\section{Results}

\section{Specimen I}

The upper ventral limb received the left adrenal vein and ran transversely in front of the abdominal aorta to open into the inferior vena cava at the level 
of the disc between the first and second lumbar vertebrae (Fig. 1). A single left renal vein formed by merging of ventral tributaries received the left ovarian vein, and then divided into the upper ventral limb and a lower branch at the level of the upper of the second lumbar vertebra (Fig. 2). After receiving a lower communicating branch which drained into the inferior vena cava with the third lumbar vein, the lower branch joined with a dorsal branch which arose from the renal hilus to constitute the lower dorsal limb of the circumaortic renal venous collar posterior to the abdominal aorta. The lower dorsal limb, which communicated superiorly with a common root of the azygos and the hemiazygos veins (Seib, 1934) and inferiorly with a tributary which joined with the second lumbar vein $(2 \mathrm{~L})$, opened into the inferior vena cava at the level of the middle of the second lumbar vertebra. The right renal vein was single and not abnormal.

The azygos, hemiazygos and accessory hemiazygos venous systems had six roots, namely the common root of the azygos and hemiazygos veins, two medial roots of the azygos vein and one medial root of the hemiazygos vein, and the lateral roots of the azygos and hemiazygos veins (Figs. 3, 4, and 5). The common root of the azygos and hemiazygos veins (CRAH) arose from the dorsal limb of the renal ring dorsomedial to the abdominal aorta and to the sympathetic nerve trunk, as described above, and then divided into three roots, namely two right medial azygos roots and the left medial hemiazygos root. Lateral roots of both the azygos and hemiazygos veins were formed by the union of the subcostal and ascending lumbar veins, and passed cranially, accepting the eleventh intercostal vein symmetrically. The azygos vein joined with the hemiazygos vein at the level of the middle of the tenth thoracic vertebra and received an accessory hemiazygos vein at the level of the seventh thoracic vertebra.

\section{Specimen II}

As shown in Figures 6, 7, and 8, in Specimen II there were four right and one left renal veins, in addition to four right and three left renal arteries. The first and second right renal veins (1RR and $2 R R$ ) were formed by the joining of three ventral tributaries, and the third and fourth right renal veins (3RR and $4 R R$ ) arose individually from the dorsal aspect of the renal pelvis. The $1 R R$ and $2 R R$ opened into the inferior vena cava at the level of the second lumbar vertebra, and, similarly, $3 R R$ and $4 R R$ at the third lumbar vertebra. In contrast, the single left renal vein was formed by merging of three ventral and two dorsal tributaries, and then opened into the inferior vena cava at the level of the second lumbar vertebra. On both sides, the testicular vein entered the lower ventral tributary of the renal vein.

In addition, the branching from the abdominal aorta of four right and three left renal arteries showed a ladder-like arrangement at the level between the second and the fourth lumar vertebrae. The distribution of each renal artery was limited to the ventral portion, dorsal portion, or renal parenchyma.

The left kideny was situated higher than the right one.

\section{Discussion}

In terms of both number and frequency, multiple renal veins on the left side are far rarer than those on the right, as a result of the difference between the two sides in embryological development. In fact, the portion of the left renal vein draining into the inferior vena cava is derived from a more central location than the analogous portion in multiple embryonic right renal veins. While two right renal veins were found to be present in five of 26 Japanese cadavers (Ohmori et al., 1983), the present case is the only known case of two left renal veins in Japan.

In the first case presented herein, the circumaortic renal venous collar (renal collar) was formed by persistence of the retroaortic venous anastomosis, namely the embryonic intersupracardinal anastomosis (McClure and Butler, 1925). As a result of this persistence of the dorsal venous anastomosis, the renal collar communicating with the collateral circulation is at risk of surgical injury (Anson and Dasler, 1961; Babaian and Johnson, 1979; Baldridge and Canos, 1987). In this study, the dorsal limb of the renal collar not only received drainage from the dorsal renal branch but also communicated with the lumbar veins and the common root of azygos and hemiazygos veins dorsomedial to the sympathetic nerve trunk and away from the inferior vena cava. Therefore, the azygos system veins and the inferior vena cava cannot be of the same embryological derivation, as was also stated by Reagan (1927) and Seib (1934), in opposition to the opinions of Hochstetter (1893) and McClure and Butler (1925). According to Seib (1934), the intersupracardinal anastomosis of McClure and Butler (1925) is comparable to the following structures, beginning with the termination of the left renal vein and continuing in a clockwise direction: left medial sympathetico-subcardinal anastomosis; intersubcentral anastomosis and subcentral vein; right medial sympathetico-subcentral and right medial sympathetico-paraureteric anastomses. The hemiazygos vein joined with the azygos vein at the level of the tenth intercostal veins, and the 


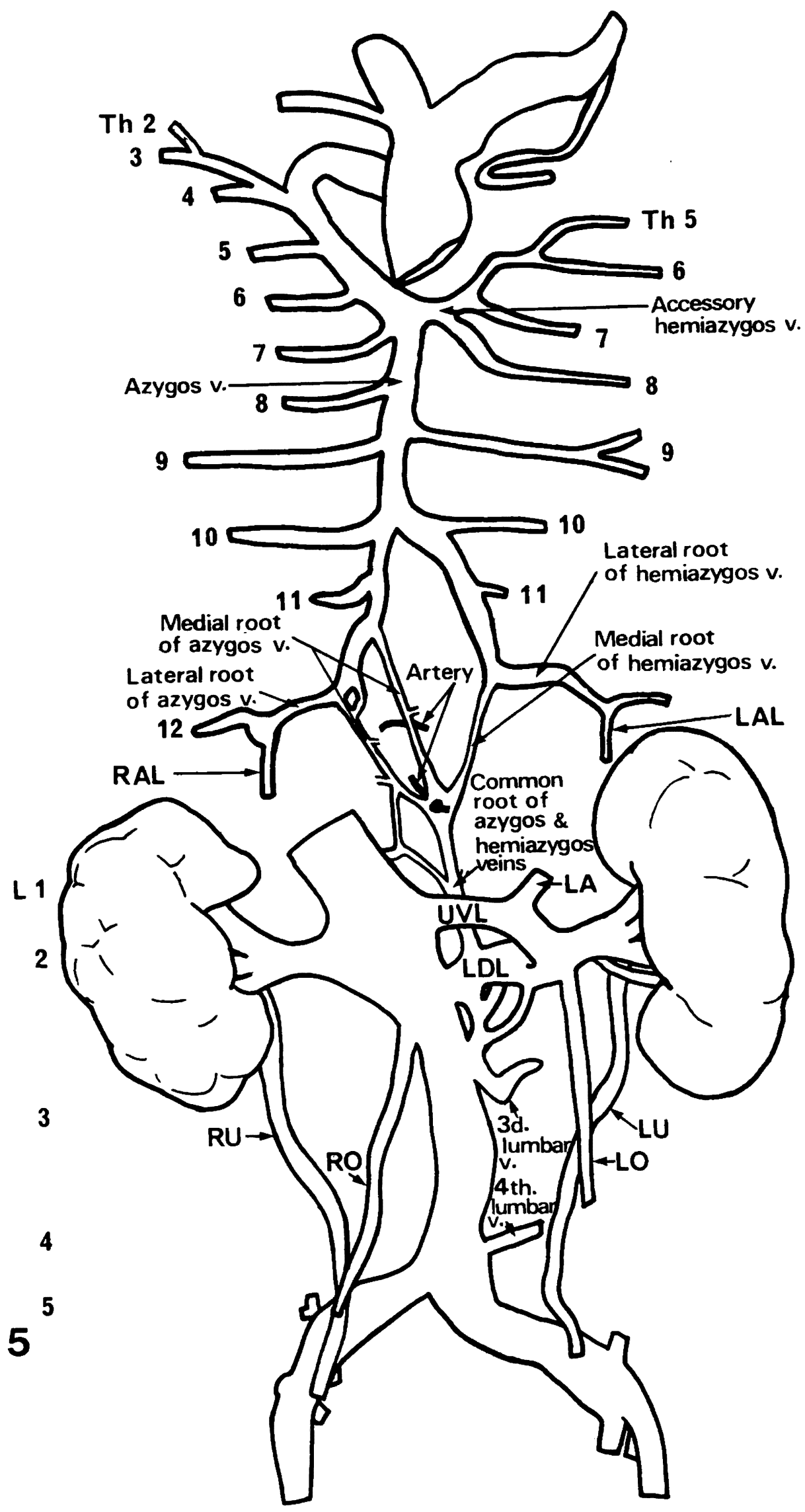

Fig. 5. Scheme of Figure 4. LA: left adrenal vein: LAL: left ascending lumbar vein; LDL: lower dorsal limb of the circumaortic renal venous collar; LO: left ovarian vein; LU: left ureter; RAL: right ascending lumbar vein; RO: right ovarian vein: RU: right ureter; UVL: upper ventral limb of the circumaortic renal venous collar. 


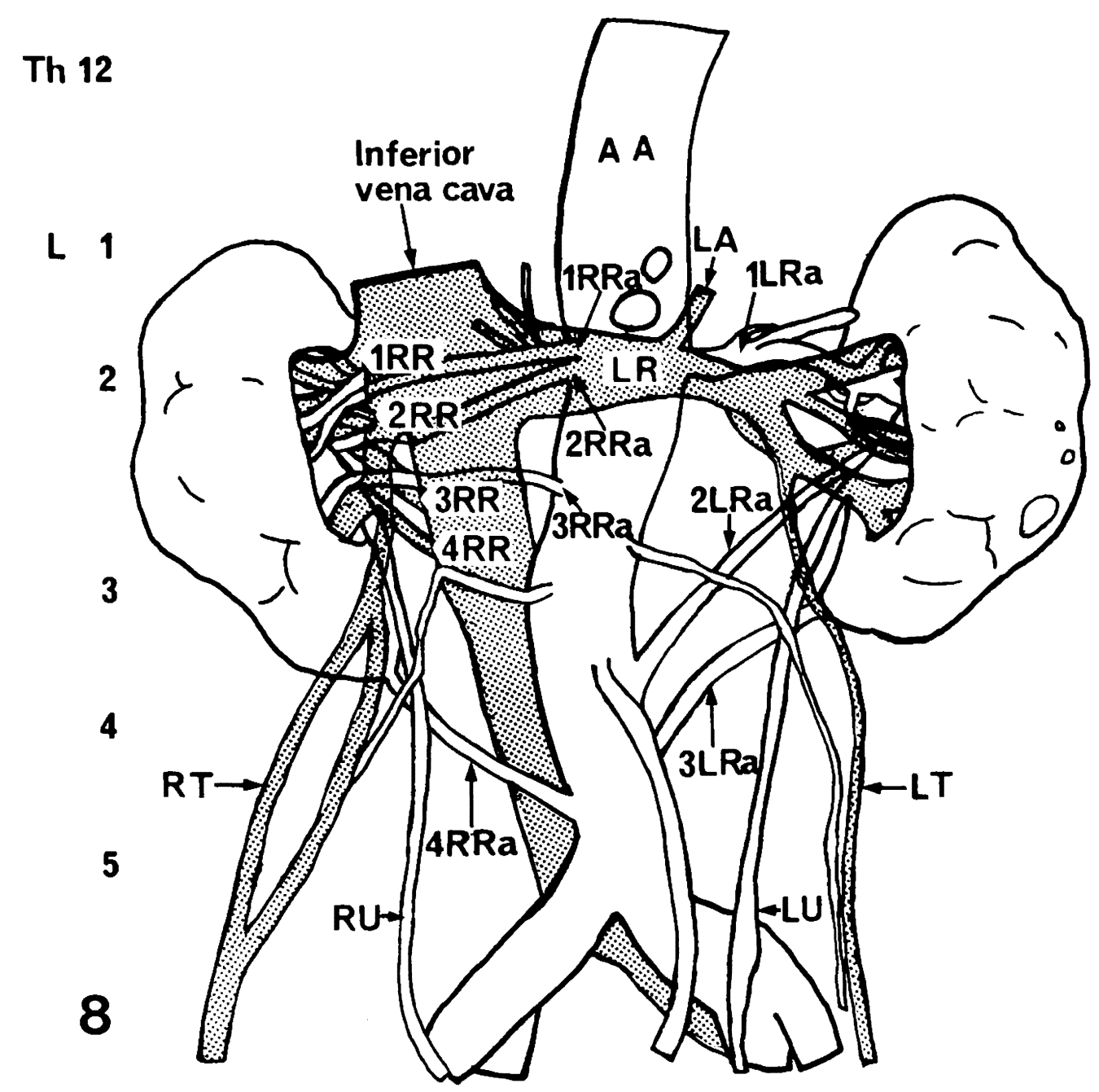

Fig. 8. Scheme of specimen II. AA: abdominal aorta; LA: left adrenal vein; LR: left renal vein; 1LRa, 2LRa, and 3LRa: first, second, and third left renal artery, respectively; LT: left testicular vein; LU: Left ureter; 1RR, 2RR, 3RR, and 4RR: first, second, third, and fourth right renal vein, respectively; $1 R R a, 2 R R a, 3 R R a$, and $4 R R a$ : first, second, third, and fourth right renal artery, respectively; RT: right testicular vein; RU: right ureter.

hemiazygos and the accessory hemiazygos veins were discontinuous. Thus, the azygos system was considered to be corresponding to Seib's (1934) transitional column venous type, which is intermediate between the double-column and the singlecolumn venous types. This formation could be explained by persistence of the retroaortic venous anastomoses at the levels corresponding to the tenth and the ninth intercostal veins. Therefore, the persistence of the thoracic retroaortic venous anastomoses is thought to be related to the renal collar which was formed by the persistence of the abdominal retroaortic venous anastomosis.

For Specimen II, it is conjectured that, at the early stage of development, five embryonic renal veins (three ventral and two dorsal) drained into the subcardinal veins on each side in a ladder-like fashion, and that, after the development of subsuparcardinal anastomoses on both sides, four of those on the right remained and entered into the right anastomosis, which became a part of the inferior vena cava, while the left veins entered into the left anastomosis which became a distal part of the single left renal vein. In addition, bilateral embryonic intersegmental arteries that arose in ladder-like fashion from the aorta (Hamilton and Mossman, 1976) partly persist and form multiple renal arteries on both sides. Variation in the renal artery would be expected from both the ontogenetic and phylogenic points of view, since it is known that reptiles have multiple renal arteries and birds usually have four to six pairs of renal arteries (Rupert, 1915). As the right renal veins and arteries of specimen II were more numerous and arose further down than the left ones, the right kidney is seemed to be fixed further down (Bergman et al., 1988).

Only two reports regarding the renal collar or four or more right renal veins or arteries have been published in Japanese. One, by Hoshiai (1939), describes two renal collars in embryos and the other, by Aso (1931), reports a renal collar and three cases of four right renal veins in embryos. Pick and 
Anson (1940) reported a case of four right renal veins, which were not accompanied by complex multiple renal arteries such as those in the present specimen II. Kramer and Grine (1980) and Seib (1934) found that the incidence of renal collar is higher in whites than in blacks. To determine more specifically whether there are racial differences in the incidence of renal collar, further studies in Asians are required.

\section{Acknowledgments}

The authors are grateful to Emeritus Professor Dr. Tadao Ohmori, Second Department of Anatomy, Fukuoka Dental College, and the late Emeritus Professor Dr. Mizuo Kiyozumi, Department of Anatomy, Faculty of Medicine, Kumamoto University, for their excellent suggestions. In addition, we appreciate the technical assistance of the late $\mathrm{Mr}$. Yonosuke Higuchi, and Mr. Katsuki Tani. Finally, we are indebted to the students of Fukuoka Dental College.

\section{References}

1) Anson, B. J. and Dasler, E. H.: Common variations in renal anatomy, affecting blood supply, form, and topography. Surg. Gynec. \& Obst 1961;112:439-449.

2) Aso, M.: Über das Gefäßsystem des Rumpfes bei der japanischen Föten. I Abteilung. Das Venensystem. Acta Anat. Nippon 1931;4:669-715. (In Japanese)

3) Babaian, R. J. and Johnson, D. E.: Major venous anomalies complicating retroperitoneal surgery. South. Med. J 1979; 72:1254-1258.

4) Baldridge, E. D. and Canos, A. J.: Venous anomalies encountered in aortoiliac surgery. Arch. Surg 1987;122: $1184-1192$.
5) Bartle, E. J., Pearce, W. H., Sun, J. H. and Rutherford, R. B.: Infrarenal venous anomalies and aortic surgery: Avoiding vascular injury. J. Vasc. Surg 1987;6:590-593.

6) Bergman, R. A., Thompson, S. A., Afifi, A. K. and Saadeh, F. A.: Cardiovascular system. In: Compendium of Human Anatomic Variation, pp. 81-82, Urban \& Schwarzenberg, Baltimore/Munich, 1988.

7) Cranston, P. E. and Halsell, A.: Inferior vena cava interruption with renal vein collar continuation: CT and MRI appearance. Comput. Med. Imag. Gr 1991;15:441-444.

8) Goswami, A. P.: Anatomical variation of the renal veins with varicosity presenting as pseudotumor of the kidney. $\mathbf{J}$. Urol 1976;116:648-649.

9) Hamilton, W. J. and Mossman, H. W.: Arteries of the limb-buds. In: Hamilton, Boyd and Mossman's Human Embryology 4th ed., pp. 271-272, Macmillan, London and Basingstoke, 1976.

10) Hoshiai, G.: A. et V. renalis der japanischen Feten. Acta Anat. Nippon 1939;13:1-23. (In Japanese with English summary)

11) Hochstetter, F.: Beiträge zur Entwicklungsgeschichte des Venensystems der Amnioten. 3. In: Säuger. Morpholog. Morphologisches Jahrbuch 20, pp. 543-648, 1893.

12) Kramer, B. and Grine, F. E.: The incidence of the renal venous collar in South African Blacks. S. A. med. J 1980; 57:875-876.

13) McClure, C. F. and Butler, E. G.: The development of the vena cava inferior in man. Am. J. Anat 1925;35:331-383,

14) Ohmori, T., Yahiro, J., Toh, H., Nakamura, T., Hamada, N., Takei, T. et al.: An anomaly in the renal arterio-venous system. J. Fukuoka Dent. Coll 1983;9:645-659. (In Japanese with English Summary)

15) Pick, J. W. and Anson, B. J.: The renal vascular pedicle. An anatomical study of 430 body-halves. J. Urol 1940;44: 411-434.

16) Reagan, F. P.: The supposed homology of vena azygos and vena cava inferior considered in the light of new facts concerning their development. Anat. Rec 1927:35:129-148.

17) Rupert, R. R.: Further study of irregular kidney vessels as found in one hundred eighteen cadavers. Surg. Gynec. Obstet 1915;21:471-480.

18) Seib, G. A.: The azygos system of veins in American whites and American negroes, including observations on the inferior caval venous system. Am. J. Phys. Anthropol 1934;19:39-163. 
Plate I
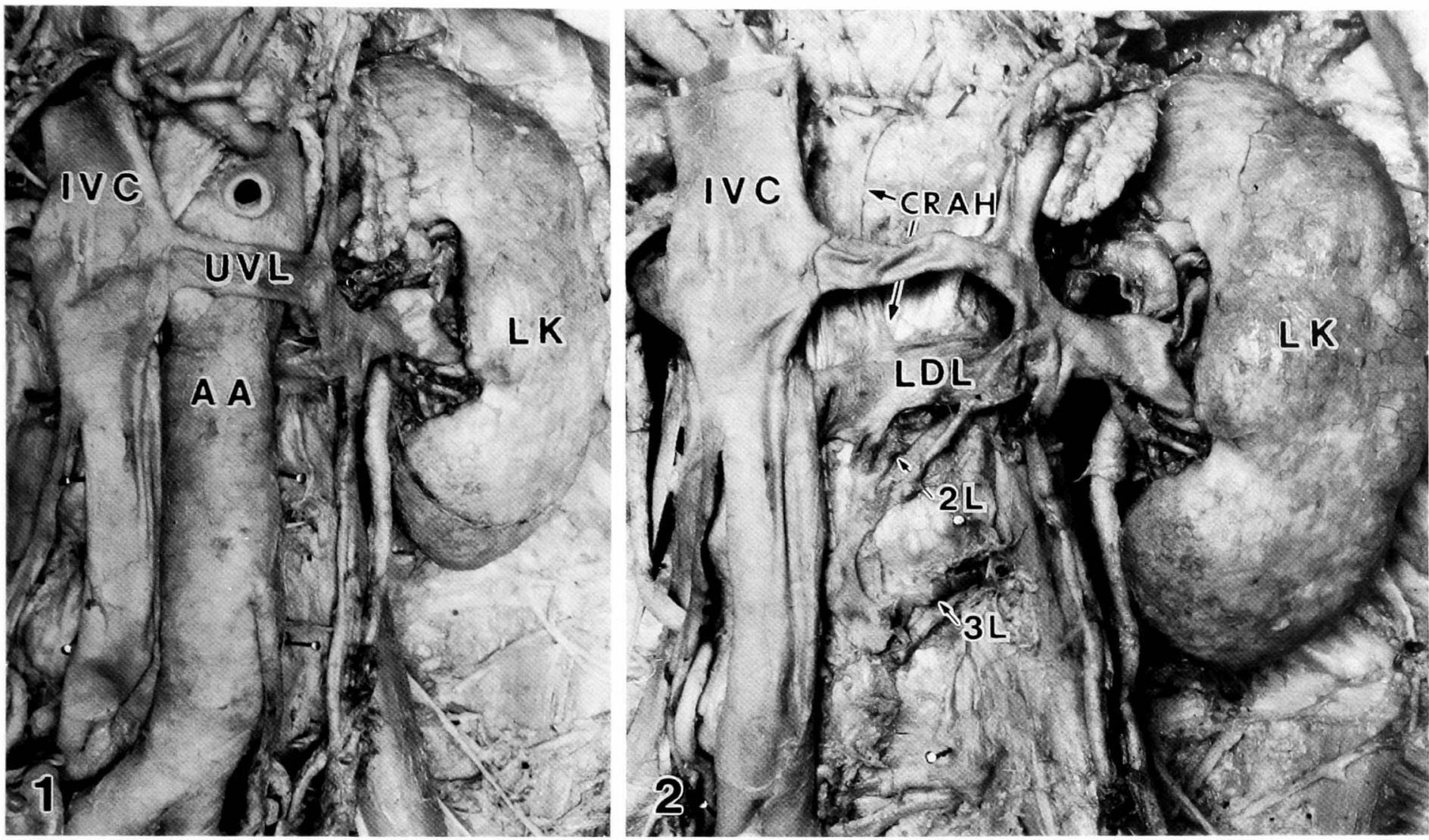

\section{Explanation of Figures}

\section{Plate I}

Fig. 1. Specimen I. A photograph of the circumaortic renal venous collar. AA: abdominal aorta; IVC: inferior vena cava; LK: left kidney; UVL: upper ventral limb of the circumaortic renal venous collar.

Fig. 2. The circumaortic renal venous collar after removing the abdominal aorta. LDL: lower dorsal limb of the circumaortic renal venous collar; CRAH: common root of azygos and hemiazygos veins; $2 \mathrm{~L}$ and $3 \mathrm{~L}$ : second and third lumbar vein, respectively. 

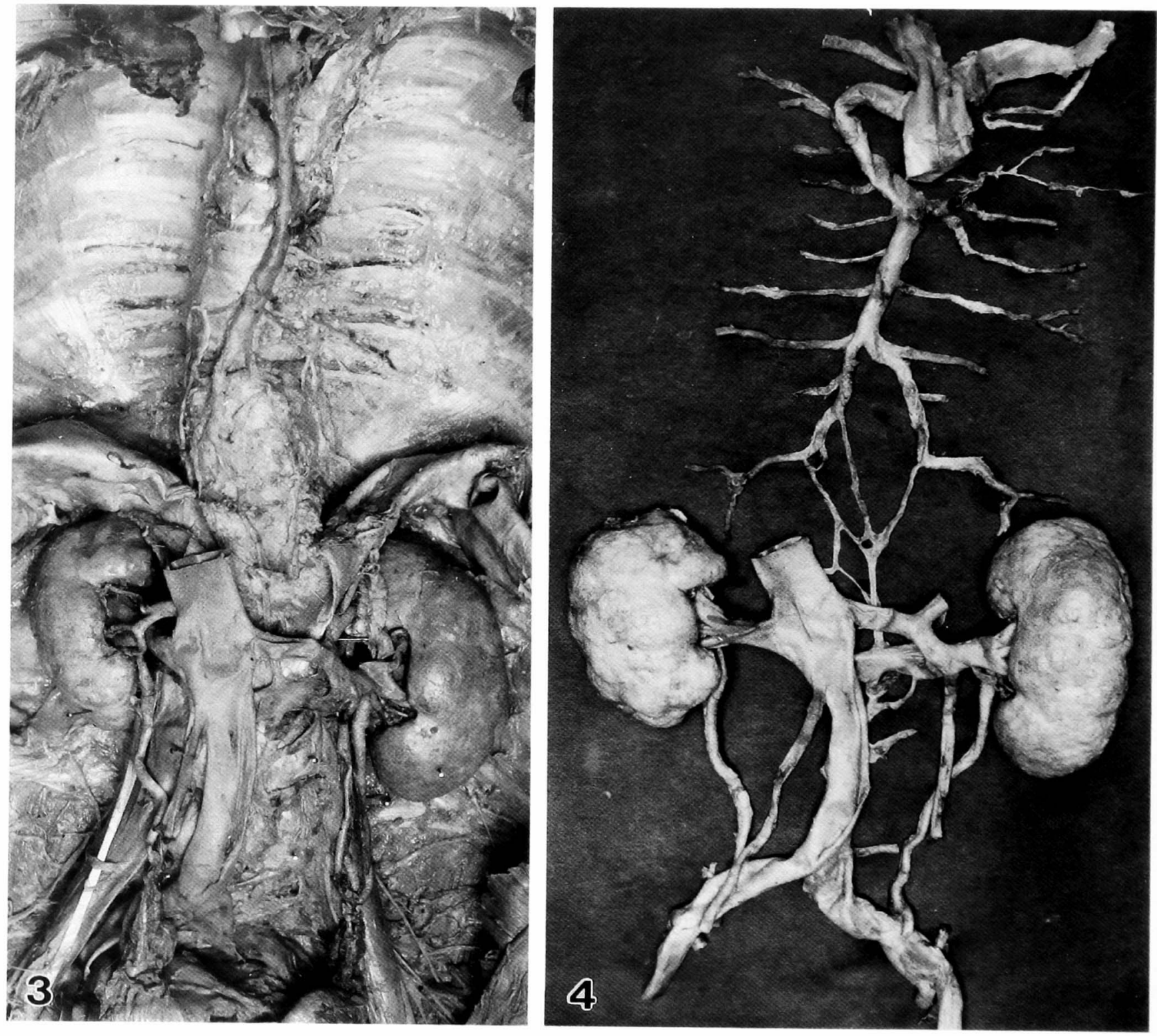

Plate II

Fig. 3. The circumaortic renal venous collar with related inferior vena cava and azygos system veins.

Fig. 4. The removed specimen in Figure 3. 
Plate III

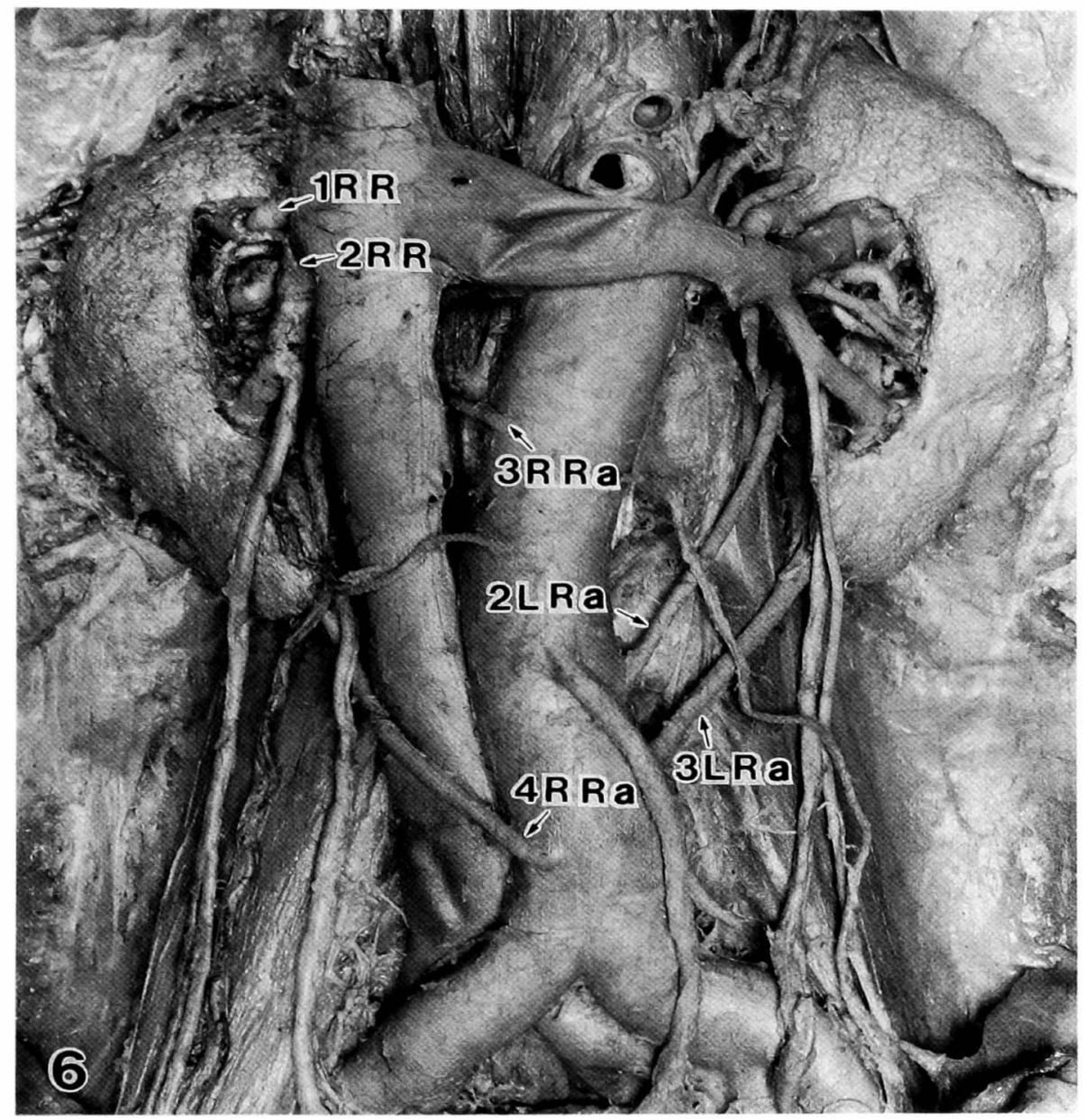

Plate III

Fig. 6. Specimen II. Four right renal veins accompanied by four right and three left renal arteries. 2LRa and 3LRa: second and third left renal artery, respectively; $1 \mathrm{RR}$ and $2 \mathrm{RR}$ : first and second right renal vein, respectively; $3 \mathrm{RRa}$ and $4 \mathrm{RRa}$ : third and fourth renal artery, respectively. 


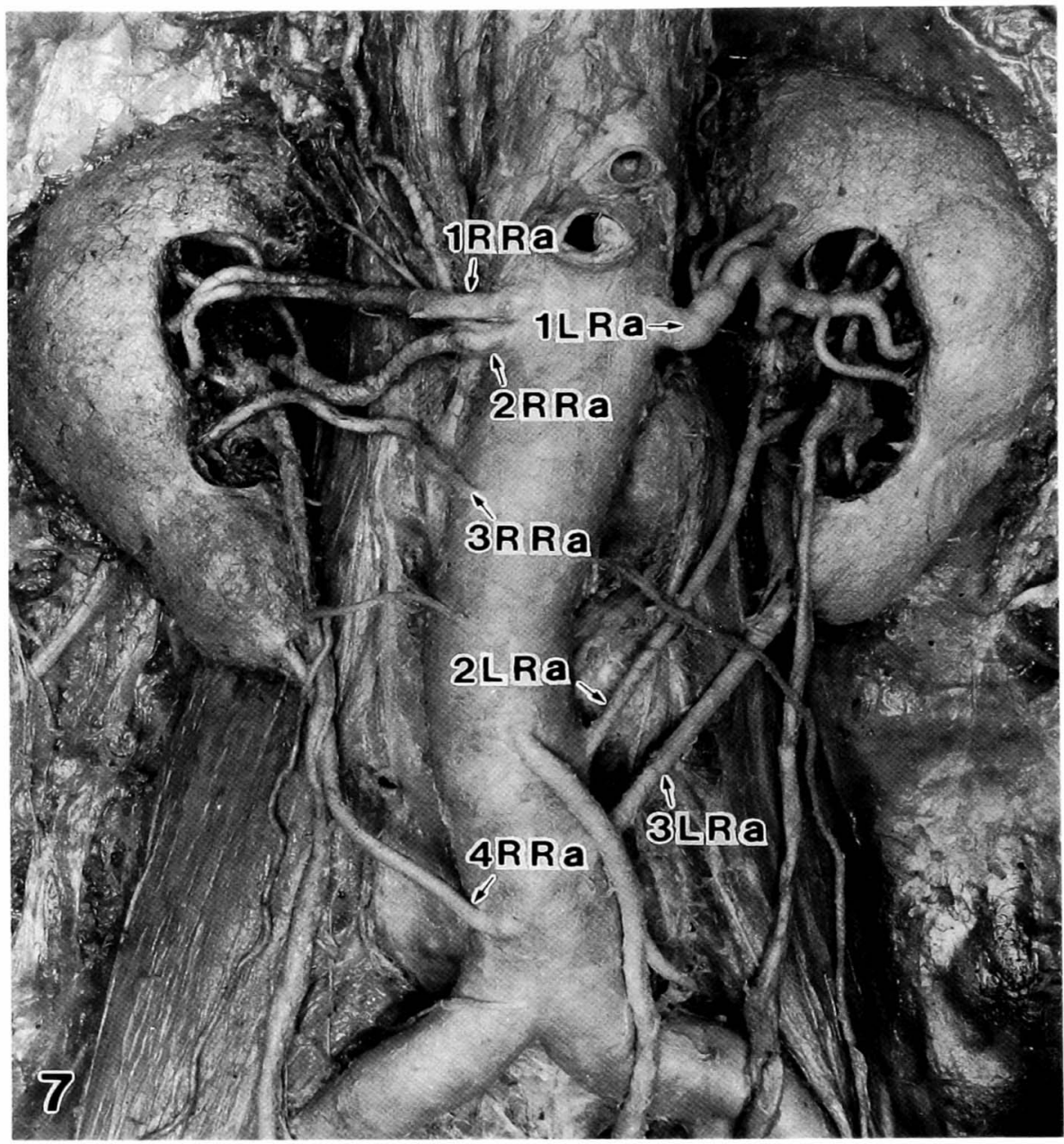

\section{Plate IV}

Fig. 7. Multiple renal arteries after removing the venous system. 1LRa, 2LRa, 3LRa: first, second, and third left renal artery, respectively; 1RRa, 2RRa, 3RRa, and 4RRa; first, second, third, and fourth right renal artery, respectively. 